\title{
perifèria
}

Número 12, mes 2010

www.periferia.name

\section{Estrategias migratorias de la población gitana búlgara en España ${ }^{1}$}

\author{
Magdalena Slávkova² - Instituto y Museo de Etnografía, \\ Academia Búlgara de Ciencias
}

\section{Resumen}

La migración laboral de ciudadanos búlgaros comenzó a partir del año 1990 y se incrementó a finales de los noventa, desarraigando a mucha gente y constituyendo flujos migratorios que siguen produciéndose y modificándose en la actualidad. España se ha convertido, además, en uno de los destinos preferidos para trabajar fuera. En ese contexto, los gitanos, junto con el resto de ciudadanos búlgaros, se incluyeron e incluyen también en dichos flujos generales hacia España. Sin embargo, han mantenido en este proceso su heterogeneidad como comunidad étnica, sobre todo a un nivel de diferentes grupos, que además pueden tener estrategias migratorias específicas. Este artículo presenta las estrategias migratorias de los gitanos búlgaros, su experiencia en el mercado de trabajo, la adaptación al sistema médico local y su vida cotidiana como inmigrantes.

Palabras clave: migración laboral, gitanos búlgaros, estrategias de inmigración en España.

\begin{abstract}
This article deals with the various migration strategies of Bulgarian Gypsies who currently live in Spain. I focus on two aspects of their way of life abroad: labour activities and cultural adaptation to the local health care system.

Following the downfall of the socialist regime in Bulgaria (1944-1989) a social and economic crisis emerged. The life of the Roma/Gypsies changed dramatically and a great many of them remained jobless. Many people turned towards cross-border labour mobility as a new economic strategy. In the migration process they left their birth places either temporarily or permanently with the hope of providing better lives for their families. In the late 1990s Spain became one of the best preferred destinations for work abroad. Like the rest of the surrounding population the Gypsies joined the common migration flows towards that destination. Within the framework of the common migration flow different Gypsy groups preserve a certain differentiation as community (mostly on group or regional-residence) level, which remains once they have settled in the country.
\end{abstract}

Key words: labour migration, Bulgarian Gypsies, immigration strategies in Spain.

\footnotetext{
${ }^{1}$ Esta investigación fue financiada por el programa individual post-doctorales del Ministerio búlgaro de educación y ciencias, Fondo de investigaciones científicas (número de contrato: DO02-355/30.12.2008).

${ }^{2}$ Enviar correspondencia a: magdalenaslavkova@yahoo.com
} 


\section{perifèria}

Número 12, mes 2010

www.periferia.name

\section{I ntroducción}

En Bulgaria en los años ' 90 del siglo XX, con la caída del régimen de gobierno socialista (1944-1989) se entra en una crisis socio-económica y como consecuencia de ella se crean flujos migratorios de obreros ilegales hacia los países de la Unión Europea. Los emigrantes dejan sus lugares natales temporalmente o para siempre con la esperanza de asegurarse un estándar de vida mejor.

España se convierte en uno de los destinos europeos preferidos y en la actualidad en el país existe una gran comunidad búlgara. Una parte de ella son los gitanos búlgaros que se incluyen en los flujos migratorios comunes pero conservan su heterogeneidad intracomunitaria. Como resultado de los procesos de movilidad laboral extrafronteriza y la emigración, los gitanos adoptan el nuevo espacio socioeconómico y se establecen a vivir en él. Ellos adoptan diferentes estrategias migratorias y por medio de ellas se adaptan a esas condiciones de vida pero, sin embargo, siguen conectados a su país de nacimiento: Bulgaria.

\section{Cronología de la " migración gitana"}

A finales de los años '90 del siglo XX después de que otros países como Grecia, Alemania, Francia, Holanda, Bélgica ya han atraído una buena parte de los gitanos, empiezan viajes en masa de representantes de diferentes grupos a España (Reyniers 1995: 11). A partir del año 2001 los ciudadanos búlgaros ya pueden residir hasta unos tres meses en el país sin visado y como consecuencia de esto el número de los viajeros aumenta significativamente. En 2007 Bulgaria llega a ser miembro de la Unión Europea y todos sus ciudadanos pueden residir en España según el régimen comunitario que incumbe a todos los ciudadanos europeos. Hasta 2009 para trabajar de una manera legal en el país todavía se necesita un permiso especial. En los últimos dos o tres años se establece un número relativamente constante de inmigrantes de Bulgaria, la mayor parte de ellos trabajando con contrato. 


\section{perifèria}

Número 12, mes 2010

www.periferia.name

En la actualidad según datos del Instituto Nacional de Estadística los ciudadanos búlgaros en España son 169.195 (INE 2010) pero según lo dicho por el Embajador de España en Bulgaria, Sr. Jorge Fuentes Monzonís-Vilallonga, los búlgaros Ilegan a unos 300.000 residentes legales e 50.000 ilegales (bTV 2010). Por mis propias observaciones en investigaciones de campo en España y en Bulgaria, puedo afirmar que entre $1 / 3$ y $1 / 4$ parte de los ciudadanos búlgaros que actualmente viven en este destino son de origen gitano. La mayor parte de los inmigrantes búlgaros viven en las comunidades de Valencia, Madrid y Castilla y León. En Castilla y León ellos son la comunidad migratoria más grande (El Mundo 2009: 17) y en algunas poblaciones los gitanos prevalecen sobre el resto de la población búlgara. En 2008 y 2009 como resultado de la crisis global financiera empieza el proceso de la así llamada migración "de retorno" durante la que los gitanos que se han quedado en el paro vuelven provisionalmente o para siempre a su país de origen.

\section{Los gitanos búlgaros: características etnoculturales}

Los gitanos presentan una sociedad heterogénea con una compleja estructura interna jerarquizada, que consta de diferentes meta-grupos, subgrupos y linajes. Los diferentes linajes mantienen una unidad y solidaridad entre ellos, pero no existe una cohesión interna entre los distintos grupos (San Román 1976: 118-136). Cada uno de los grupos se diferencia de los demás por sus características etnosociales y culturales. Las distintas uniones se diferencian entre sí en función de diversos criterios: identidad preferida, lengua materna, religión, profesión tradicional y modo de vida en el pasado y en la actualidad (Marushiakova, Popov 1997). Sólo se identifican entre sí como gitanos en cuanto opuestos a los payos (San Román 1976:195).

Los gitanos en Bulgaria oficialmente son 370.908 (NSI 2001) pero su número real llega a unos 800.000 (Liégeois 1999). Una parte de los grupos tienen identidad gitana (y respectivamente hablan dialectos de la lengua gitana romanés). Estos están distribuidos por todo el territorio del país: kaldaraši (caldereros), burgudžhii (cuchilleros), muzikanti (músicos), erlii (lugareños), xoraxane roma (gitanos turcos), dasikane roma (gitanos búlgaros), kalajdžhii (quincalleros), etc. En 


\section{perifèria}

Número 12, mes 2010

\section{www.periferia.name}

Bulgaria también reside población rumanohablante que en su lengua materna se define como rudari (o lingurari y ursari) ${ }^{3}$ pero muchas veces ante la población circundante se presentan como viejos rumanos o valacos. A causa de su vida seminómada en el pasado, su mentalidad y ciertas características físicas, se perciben por los búlgaros como gitanos rumanos (Sikimić 2005). Otra parte de los gitanos tienen conciencia nacional turca o se definen con la denominación neutra millet (pueblo) y los dos grupos hablan turco. La última parte de ellos tienen conciencia nacional búlgara y se definen como viejos búlgaros o búlgaros del tiempo del kan Asparukh (la idea mítica aceptada como verdad histórica de que son sucesores de gente que ha llegado a las tierras búlgaras en el s.VII junto con el kan protobúlgaro Asparuh). La población circundante los llama palomas grises.

Lo más común es que los gitanos musulmanes vivan en Bulgaria del Este y los ortodoxos en Bulgaria del Oeste. Según la tradición los musulmanes son los gitanos turcos (xoraxane roma), millet, los gitanos que se perciben como turcos, erlii, muzikanti, kalajdžhii, etc. y los demás son ortodoxos. En los últimos 20-30 años los gitanos van incorporándose a las iglesias evangélicas y resulta que los más difundidos son los del movimiento pentecostal (Slavkova 2007).

La inclusión de los gitanos en los flujos migratorios generales hacia España se ve diferenciada con arreglo a los grupos (Marušiakova, Popov 2008). En el pasado una parte de ellos eran nómadas y llevaban una vida semimóvil. Durante los meses de más calor la familia recorre el país ejerciendo su labor tradicional con la que se gana el pan y en invierno se queda en su población de residencia. Los últimos grupos nómadas empiezan a llevar una vida sedentaria en los años '60 del s. XX, cuando el Consejo de ministros promulga un decreto con el que reglamenta una sedentarización obligatoria y fijación de lugar de residencia concreto para todos los nómadas (Postanovlenie No. 258/17.12.1958). Ex-nómadas son, por ejemplo, los kardaraši, burgudžhii, rudari, etc. En general emigran representantes de las dos comunidades ex-nómadas y gitanos sedentarizados. De los gitanos que llevaban

\footnotetext{
${ }^{3}$ Lingură (rum.) - cuchara de madera y urs (rum.) - oso.
} 


\section{perifèria}

Número 12, mes 2010

www.periferia.name

una vida nómada en el pasado los más activos resultan los rudari (Slavkova 2008). Una de las razones más importantes para que los rudari se vayan a España es la proximidad del castellano a su lengua materna y la posibilidad de encontrar rápidamente un trabajo como obreros ilegales y después legalizar su estancia con relativa facilidad. En resumen entre los que se van a trabajar en el extranjero predominan los representantes de estos gitanos cuyos bisabuelos se han asentado hace siglos en las tierras búlgaras: xoraxane roma, millet, los gitanos que se perciben como turcos, erlii, мuzikanti, кalajdžhii, dasikane roma, los viejos búlgaros, etc.

\section{Modo de vida en España: estrategias migratorias}

En el curso de la movilidad laboral extrafronteriza los gitanos adoptan varias estrategias migratorias. Por medio de ellas los diferentes grupos se adaptan a su nuevo modo de vida en el extranjero. Estas estrategias en la mayoría de los grupos se parecen teniendo en cuenta el hecho de que están en las mismas condiciones, desarrollan semejantes actividades económicas y son asumidos por los españoles como búlgaros en general. Pero de todos modos las comunidades gitanas conservan sus límites entre sí. Las estrategias son las siguientes: viaje con una estancia a corto plazo en el destino como meta; establecimiento en el país; toma de la decisión de instalación en España.

La razón principal por la que se da una gran oleada migratoria de gitanos búlgaros a España es económica. El paso de una economía centralizada a una economía de mercado en los años ' 90 del siglo $X X$ se ve relacionado con una etapa de alta inflación y paro que afecta a la población de todo el país. Muchos gitanos se quedan en el paro con el cierre de las cooperativas agrarias de las aldeas (Marushiakova, Popov 2001: 370-388). La población gitana se adapta a las nuevas condiciones de vida a través de diferentes estrategias económicas. Una parte significativa de ella se orienta a la movilidad laboral extrafronteriza como forma de adaptación.

Los gitanos rumanohablantes son el primer grupo cuyos representantes viajan en masa por España. Ellos llegan en autobuses a Madrid donde empiezan a trabajar y más tarde se dispersan por poblaciones pequeñas en las diferentes provincias del 


\section{perifèria}

Número 12, mes 2010

www.periferia.name

país (Viruela Martínez 2008: 169-194). Después de ellos a este destino se orientan otros grupos también: dasikane roma, xoraxane roma, erlii, los viejos búlgaros, etc. Los rudari en muchos casos crean flujos migratorios autónomos y a menudo involucran en ello a la población búlgara circundante. Al contrario, los demás grupos gitanos se unen a los grupos búlgaros en las corrientes migratorias comunes. Los últimos en dirigirse a este destino son los gitanos de conciencia nacional turca que son parte de las redes regionales de la población turca y llegan a ser parte de las oleadas comunes búlgaras. Los viajes de los muzikanti y de los kardaraši en el extranjero son una excepción de la regla común. Entre el grupo de los kardaraši la movilidad extrafronteriza en gran parte de los casos obtiene una forma específica: la salida de adolescentes o de mujeres jóvenes casadas acompañadas por la suegra o algún hombre familiar con el fin de ratear en el extranjero. A España ellas se van a "trabajar" a las ciudades grandes: Madrid, Barcelona, Valencia y se quedan varias semanas. En realidad, los casos de los kardaraši son excepciones y presentan un porcentaje mínimo. Los músicos tienen sus redes migratorias regionales y se establecen en las poblaciones turísticas donde pueden ganarse el pan tocando. Ellos trabajan más que nada como músicos callejeros. Los interlocutores comparten que el tocar en la calle se prefiere por el fácil acceso, el buen dinero que se gana y la reacción positiva por parte de los españoles, a diferencia de los búlgaros que lo perciben como otra manera de pordiosear. Los músicos tocan en Bilbao, Pamplona, Barcelona, Madrid, etc. Y por lo general trabajan de uno a tres meses en el extranjero. En la mayoría de los casos esta actividad se realiza sólo por hombres, pero a veces entre los músicos callejeros puede haber matrimonios. Por ejemplo dos de mis informadores han trabajado como músicos callejeros en Barcelona. La mujer interpreta canciones búlgaras y gitanas al son del acordeón de su marido. Más tarde empiezan a tocar en la ciudad francesa de Perpiñán. En el extranjero se quedan uno, como mucho dos meses, regresan a su país y después vuelven otra vez. La mujer es evangélica pero va a cultos sólo cuando está en Bulgaria, donde visita la iglesia evangélica de pentecostales de su ciudad natal. 


\section{perifèria}

Número 12, mes 2010

www.periferia.name

La mendicidad es una estrategia de adaptación típicamente gitana y a ella se orientan los representantes de grupos que en su país no la han practicado (por lo menos en las últimas generaciones). Sin embargo, a menudo este es un trabajo provisional mientras encuentran otro que lleve más ingresos. Por ejemplo los gitanos de Pazardzhik (Bulgaria del Sur) mendigan delante de las iglesias católicas de Murcia, habitualmente ambos: hombre y mujer, y sólo cuando no hay trabajo en el campo. Los informadores dicen que en España "no es vergonzoso" mendigar cuando estás en apuros y también que los españoles siempre dejan monedas en un vaso de plástico con una sonrisa.

Los primeros emigrantes viajan a España sin tener la mínima idea de cómo es el país, el modo de vida, las relaciones entre la gente o conocimientos del castellano. Al principio a menudo en el extranjero va solo un miembro de la familia y en este caso las mujeres se mueven en igualdad con los hombres. La razón por la que habitualmente las mujeres se van primero es que para ellas resulta más fácil encontrar trabajo en las casas de los españoles como servicio doméstico. Característica peculiar de la movilidad laboral de los rudari en los países mediterráneos por ejemplo es su feminización (Slavkova 2010: 283-308). Los viajeros se van con la intención de establecerse en el extranjero y después hacer venir a su familia. En el país de origen se queda la gente mayor que se ocupa de los nietos pequeños. Dentro de cierto tiempo ellos también se van a España donde empezarán a acudir a la escuela.

Llegando a España los gitanos búlgaros se encuentran en un país de estándar de vida más alto y condiciones del mercado laboral diferentes. Ellos en general repiten los modelos de las emigraciones de los búlgaros y realizan actividades económicas en las mismas esferas. Los gitanos reducen el déficit de mano de obra barata. La mayoría empiezan a trabajar sin contrato y después con la cooperación de sus contratantes legalizan su estatuto. Durante este tiempo llegan a ganar la confianza de la gente para la que trabajan y comprobar que son buenos obreros. Los primeros gitanos venidos encuentran trabajo en el sector agricultor. El trabajo en este sector es temporal y consiste en la cosecha/ recolección de diferentes tipos de fruta y verdura. A este tipo de ocupación se orientan hombres y mujeres 


\section{perifèria}

Número 12, mes 2010

www.periferia.name

representantes de diferentes grupos (rudari, xoraxane roma, dasikane roma, erlii, millet). Independientemente de que puede que nunca se hayan ocupado de agricultura en su país de origen. Bastante a menudo las mujeres empiezan a trabajar como servicio doméstico (internas o externas) o trabajan como limpieza en restaurantes, hoteles, oficinas. Ellas son contratadas en las casas españolas para cuidar de enfermos, gente mayor o niños pequeños, limpian la casa, hacen la compra, cocinan. Estas actividades son de sueldo bajo y se consideran poco prestigiosas.

Encontrar un puesto de trabajo es una manera de adaptarse a las nuevas condiciones de vida. Al principio los gastos se limitan al mínimo, se buscan pisos de alquiler baratos y no se gasta dinero extra. Los primeros inmigrantes, por ejemplo, incluso duermen en los parques o en los asilos de Cáritas porque no tienen ningún conocido en la ciudad que les pueda ayudar. Ninguno de los recién llegados tiene la intención de quedarse a vivir en España pero con el transcurso del tiempo la situación cambia, especialmente cuando llegan los familiares. La adaptación de cada familia es de diferente duración y dificultad. La familia es una garantía para la adaptación más rápida a las nuevas condiciones de vida, mantiene la solidaridad y es un factor importante para la conservación y reproducción de la tradición etnocultural. Naturalmente los gitanos recién llegados buscan trabajo por la línea familiar a diferencia de los búlgaros que cuentan también con sus amigos. Las relaciones con españoles son restringidas. Independientemente de que los miembros de la familia se junten a vivir en España, durante mucho tiempo la estrategia básica de los emigrantes provisionales es ganar dinero en el extranjero que se ahorra para vivir después con él en el país natal. El dinero ahorrado se invierte en la compra inmobiliaria en su país. Se construyen casas bonitas y de muchos pisos en la población de origen. Los inmigrantes envían cada mes dinero a sus familiares.

La vida en España empieza poco a poco a causar molestias a los recién venidos y ellos se enfrentan con una serie de dificultades. Uno de los problemas más importantes con el que se encuentra cada inmigrante es el acceso a asistencia médica y la adaptación al sistema médico local. A eso se pueden añadir las 


\section{perifèria}

Número 12, mes 2010

www.periferia.name

diferentes nociones tradicionales que los gitanos tienen y las que se diferencian de las nociones de los españoles como queda claro en los ejemplos a continuación. La buena salud se valora por todos y la mayor preocupación de los padres es la salud de sus hijos. Los inmigrantes prefieren trabajar con un contrato laboral por tiempo indefinido y estar registrados porque de esta manera tienen acceso a la asistencia médica gratuita. La Salud Pública española es desconocida para los inmigrantes y la falta de conocimientos de la lengua limita su acceso a ella. La información sobre la Salud Pública y que pueden aprovecharla los residentes en España, se pasa solo de boca en boca porque el enfermo comparte su experiencia con sus parientes. Al principio se va a ver a un médico solo cuando se presenta alguna emergencia y no se acude a exámenes médicos de profiláctica. Los primeros meses se piensa en encontrar más rápidamente piso de alquiler y trabajo y el cuidado por la propia salud se queda atrás. En ella se piensa en caso de emergencia y en la mayoría de los casos los gitanos prefieren volver a Bulgaria para buscar asistencia médica. Los servicios médicos son demasiado caros en el extranjero para que los inmigrantes puedan permitirse el lujo de pagar por ellos. De todos modos cuando se trata de la salud de sus niños, los padres en todos los casos pagan la asistencia médica necesaria aunque después puedan tener serias dificultades financieras y tengan que pedir dinero prestado. La visita a un médico provoca mucha más molestia en los inmigrantes porque no siempre pueden explicar cómo te sientes en una lengua extranjera. Existe la regla tácita de que cuando se trata de la salud ningún inmigrante puede negar ayuda a un necesitado independientemente de si es búlgaro o gitano. El enfermo siempre va acompañado por un conocido o alguien que sabe bien castellano y podrá colaborar en la conversación con el personal médico. Es una costumbre que las mujeres acompañen a otras mujeres especialmente cuando se trata de los delicados "asuntos femeninos". Este es el inicio del cambio porque según la tradición entre los grupos gitanos no se acepta el comentario público de temas relacionados con la salud de alguien del grupo y mucho menos compartirlo con búlgaros. La noticia desagradable de la enfermedad de alguien del grupo se conserva en secreto para preservar al enfermo de una discusión pública y probable aislamiento. 


\section{perifèria}

Número 12, mes 2010

www.periferia.name

Las mujeres que trabajan en las casas de los españoles son las primeras que se hacen una idea de las costumbres de los lugareños. Ellos consideran a los españoles como menos higiénicos. Por ejemplo no pueden entender por qué tienen que quitar el polvo en la casa todos los días aunque lo hacen sin quejarse. Por otra parte se quedan sorprendidas por qué la ropa de todos los días y la ropa interior se deben lavar juntas en la lavadora. En los grupos gitanos la parte superior del cuerpo se considera "limpia" y la inferior "sucia" y por eso según su entendimiento todos los tipos de ropa se deben lavar por separado (Sutherland 1986)

Poco a poco las familias gitanas empiezan a adaptarse a la manera de vida española, los niños se matriculan en las escuelas públicas locales y se socializan en el ámbito español. Dentro de cierto tiempo cuando el patrón ya tiene confianza en los obreros de Bulgaria que trabajan para él, él coopera para que los siguientes familiares llegados encuentren trabajo. De la misma manera los gitanos pueden contar con sus vecinos españoles con los que comunican a diario. Así por ejemplo la suegra, la nuera, la hija, la sobrina pueden trabajar como servicio doméstico en las casas de varios españoles que son familiares. Los hombres se orientan a la búsqueda de un trabajo más lucrativo frecuentemente en el sector de la construcción. Ellos empiezan como obreros y pueden llegar a ser encargados. Como obreros de construcción trabajan hombres de diferentes grupos gitanos. Por lo general, la posición de los hombres es mejor que la de las mujeres porque ganan más y realizan un trabajo más especializado. Muy a menudo sucede que ellos aprendan el oficio en el extranjero aunque nunca antes hayan trabajado como constructores en su país de origen. Otra variante de trabajo es la de conductor en diferentes empresas, mecánicos en talleres de reparación, técnicos, etc. Aunque encuentran trabajo más fácilmente que los hombres, el mayor "dolor" de las mujeres es la falta de perspectivas de crecimiento en su profesión o de encuentro de un trabajo de más prestigio. En España se vive tranquilamente pero la mayoría no tendrán la oportunidad de progresar porque en su profesión no existe jerarquía y ellos saben que se quedarán mujeres de limpieza durante toda su vida. 


\section{perifèria}

Número 12, mes 2010

www.periferia.name

Algunos de los gitanos búlgaros son lo suficientemente astutos como para darse cuenta dentro de cierto tiempo que pueden llegar a ser "jefes" en la esfera de la agricultura. Por ejemplo el hombre se pone de acuerdo con el propietario español de la tierra que necesita mano de obra y le asegura el número necesario de gente (puede también llamar a sus familiares de Bulgaria). Además de tener la obligación de llevarles todos los días al campo, sus pagos diarios también se reparten por él y de esa manera él tiene la oportunidad de llevarse una parte de la suma como remuneración por la actividad que realiza.

Algunos de los gitanos compran pisos con crédito y a la vez siguen invirtiendo en la compra de inmuebles en Bulgaria. Poco a poco su círculo de conocidos se ensancha y empiezan a contactar con más españoles o búlgaros con los que viven en la misma ciudad o barrio. Sin embargo, ellos no mantienen ningún tipo de contacto con los gitanos locales con los que desarrollan diferentes actividades económicas en diferentes sectores. Los únicos inmigrantes gitanos con los que podrían tener relaciones o esbozos de este tipo de relaciones son los evangelistas. Algunos de los gitanos que mendigan delante de las iglesias católicas de Murcia me mostraron la tarjeta de visita de un gitano evangélico al que intentaban localizar para que les ayudara a encontrar un trabajo mejor (Slavkova 2008).

En general los gitanos que tienen la posibilidad de beneficiarse de los servicios de los hospitales públicos evalúan de una manera positiva la asistencia en ellos. Se quedan agradablemente sorprendidos con las buenas condiciones en los hospitales y el trato amable a todos los pacientes. Poco a poco se dan cuenta que resulta mejor someterse a tratamiento en España en vez de tener gastos innecesarios para su viaje a Bulgaria, la asistencia médica y en algunos casos los pagos en mano a los doctores para que les presten la atención necesaria. Algunas mujeres por ejemplo prefieren dar a luz en España y no en Bulgaria por las siguientes razones: la ayuda financiera por el recién nacido supera diez veces la de su país natal y la asistencia en los hospitales es mucho mejor. Para los pacientes gitanos también tiene importancia el hecho de que los españoles acepten todos los llegados de Bulgaria como búlgaros y no les tratan de una manera diferente porque son gitanos. A esto se puede sumar también el acceso a medicamentos baratos y de 


\section{perifèria}

Número 12, mes 2010

www.periferia.name

buena calidad que se pueden obtener con receta y para los que se paga un porcentaje de su precio. Por ejemplo una persona que tiene la seguridad social se va a un hospital público, dice que está enferma y le pide al médico de guardia que le escriba una receta con su nombre, después compra los medicamentos necesarios y más baratos y los envía a su familia en su país. Por eso una parte invariable del equipaje en los viajes al propio país son las medicinas españolas. Los gitanos adquieren la costumbre de ir con regularidad a los hospitales y hacerse chequeos médicos profilácticos. Por otra parte ellos siempre dicen que todo está muy bien pero que "en España es mejor que no te enfermes". En este caso tienen en vista el sistema de tratamiento más torpe, la falta de confianza en la capacidad del personal médico, algunas costumbres higiénicas que aceptan con dificultad. Por ejemplo, la mayoría de las informadores subrayan que en Bulgaria, en el día del nacimiento del niño solo el padre tiene el derecho de verle y en no más de unos minutos y el resto de la familia se queda en el pasillo esperando. Según las creencias tradicionales hasta el cuadragésimo día, periodo en que son vulnerables, la madre y el bebé se tienen que aislar para protegerlos de magias y mal de ojo. A los interlocutores les indigna que en España los familiares lleguen el mismo día y empiecen a besar y a abrazar al bebé y al mismo tiempo se muestren "amables" con todos los demás recién nacidos. En muchos casos a causa de la desconfianza en el personal médico y la torpeza del sistema de sanidad, los gitanos prefieren curar las enfermedades más graves en su país natal. Una interlocutora de los kalajdžhii comparte que hace unos meses su madre se enfermó gravemente. En el hospital público local le hacen varios exámenes mensuales pero su estado empieza a empeorar y ellos siguen sin señalar el día de la operación por el hecho de no haber podido diagnosticarla con exactitud. El esposo de mi interlocutora vende su coche porque necesitan dinero para cubrir los gastos del tratamiento. Después ella, embarazada de seis meses con su madre se van a Bulgaria. Allí operan a la enferma inmediatamente. Urge quedarse en Sofía por cierto tiempo para que la enferma se recupere. Mientras tanto el propietario del restaurante donde trabajó como ayudante cocinera la despide y su hija procede contra él para obtener una indemnización. 


\section{perifèria}

Número 12, mes 2010

www.periferia.name

El cambio drástico en el modo de vida, los problemas de adaptación en el extranjero tienen su reflejo en estado de salud físico y psíquico de los inmigrantes. La tensión se acumula con los años y empieza a ejercer su influencia dentro de cierto tiempo y como resultado de eso los inmigrantes llegan a ser más susceptibles a diferentes enfermedades. Los gitanos en muchos casos resultan más estables psíquicamente que los búlgaros porque se instalan a vivir en España con la mayoría de sus parientes. Así por ejemplo en una población pequeña cerca de Burgos vive una familia gitana de 20-25 miembros (representantes del grupo de los millet). A esto se debe añadir la adaptación al clima diferente cuya humedad o altas temperaturas de verano también tienen su reflejo en la salud y la capacidad para el trabajo. Por ejemplo una parte de los inmigrantes que viven en la región de Burgos cuentan que se han instalado allí por el clima más saludable mientras que sus hijos al sur no pudieron adaptarse. No es ocasional el hecho de que la mayor comunidad de inmigrantes en Castilla y León sea búlgara. Muchos de ellos afirman que en este lugar la naturaleza les recuerda mucho la de su país.

Los inmigrantes experimentan dificultades también en la adaptación a la cocina local. Los gitanos no pueden entender por qué los españoles de algunas provincias comen cinco veces al día. Un interlocutor comparte que al principio nada te parece sabroso incluso el pan es diferente. Con el transcurso del tiempo la familia se adapta al régimen alimenticio local pero en la alimentación cotidiana y festiva predominan los platos búlgaros. Así se compra el pan que más les recuerda el búlgaro. Preparar tarator (sopa fría de yogur, agua, aceite de girasol, pepinos y ajo) resulta una tarea nada fácil hasta encontrar el yogur cuyo sabor es el más adecuado. En la cocina de los inmigrantes se prefieren la musaka, la sopa de lentejas, la sopa de frijoles, el tarator, las albóndigas, la ensalada shopska, la banitza (pastel de hojaldre) con queso. Las costumbres alimenticias tienen que ver también con las nociones tradicionales de salud. Según las creencias tradicionales si a una mujer embarazada le apetece comer algo su deseo se tiene que satisfacer para que el niño no nazca con cicatriz. Un caso típico es el siguiente. Una interlocutora de los viejos búlgaros vive con su familia en Burgos. Una vez cuando estaba embarazada de su segundo hijo, sintió ganas de comer banitza con queso 


\section{perifèria}

Número 12, mes 2010

www.periferia.name

búlgaro pero no podía encontrar semejante cosa en ninguna parte. Por eso la preparó ella misma estirando la masa con el palo de la escoba porque en España no había de dónde comprarla.

A los emigrantes les llaman mucho la atención los hábitos higiénicos de los lugareños y poco a poco se crean una opinión de ellos. Los gitanos valoran la higiene dentro de la casa. Mantener la casa limpia es obligación de las mujeres jóvenes de la familia - la nuera, las hijas solteras- y se controla por las mujeres mayores. Para ellos, sin embargo, el espacio de la vivienda termina con la puerta de entrada. El cuidado por la limpieza en la casa muchas veces no se ve relacionado con el mantenimiento del ámbito circundante. Así son las cosas también para los búlgaros. Cuando llegan a España a los gitanos les causa muy buena impresión las calles limpias y en general el modo de vida más ordenado, que ellos comparan con la mala infraestructura en algunos lugares de Bulgaria. A su llegada a Bulgaria esto es una de las cosas que les molesta más. La diferente actitud frente a la limpieza del espacio común fuera de la casa lleva a tensión o malentendidos con la población local. A los gitanos de Bulgaria tal como se han acostumbrado a hacerlo en su propio país, también en España les gusta en los días festivos reunirse en la plaza del pueblo en que viven. Se encuentran madres con hijos, parientes, vecinos búlgaros y gitanos que se cuentan unos a otros cómo han pasado la semana, comentan los chismes de la comunidad. En estos encuentros ellos comen pipas de girasol tirando las cáscaras al suelo lo que les parece inadmisible a los españoles. Ellos lo hacen en los locales aunque las cafeterías pueden quedar cerca de o en la plaza misma. Por ejemplo en Íscar (Valladolid) hay un locutorio búlgaro. En la plaza enfrente de él se reúnen en los días festivos búlgaros y rudari. Antes se reunían en la Plaza Mayor delante del edificio del ayuntamiento pero por su costumbre de comer pipas y tirar la cáscara, el municipio se vio obligado a expedir una orden por la que se prohíbe la contaminación de la plaza. Los gitanos por su parte no pueden aceptar la costumbre de los españoles de tirar basura al suelo de los locales en los que comen. Por eso ellos siguen pensando que los españoles son menos higiénicos que ellos.

En España los gitanos adquieren costumbres que no tenían en su país. Por ejemplo 


\section{perifèria}

Número 12, mes 2010

www.periferia.name

hasta hace poco en Bulgaria se desconocía la separación de la basura por materiales. Todos los gitanos en España se acostumbran rápidamente a esto e incluso se sorprenden por la "suciedad" del propio país. Resulta que los gitanos sin problema aceptan las leyes y las reglas que se tienen que cumplir en el extranjero como resultado del hecho de vivir en la sociedad española.

Con el transcurso del tiempo los gitanos se asientan en España y empiezan a sentirse bien en su nuevo entorno. Ellos encuentran diferentes nichos económicos de realización por medio de los que se pueden asegurar unos ingresos más estables. Una variante semejante es volverse autónomo (Markova 2008: 153-178). Por el hecho de que llegando a España los gitanos no disponen de un capital grande, no conocen el mercado y de hecho no son competitivos, esta es una variante alternativa de adaptación y estrategia de realización económica. Poco a poco el autónomo llega a formar una pequeña empresa familiar para contratar a parientes y los ingresos se quedan en la familia. Para ellos existen varias posibilidades para desarrollar un pequeño negocio familiar: abrir una tienda de mercancías búlgaras, un bar o un restaurante que ofrece cocina balcánica, un locutorio o registrarse como autónomo que va a realizar actividades de construcción. Por ejemplo alguno de los hombres se registra como autónomo y contrata $3 \circ 4$ ayudantes más y todos juntos realizan actividades de construcción en las casas de los españoles, más frecuentemente en las poblaciones más pequeñas que no han sido integradas por las empresas de construcción locales. Parte de los músicos que trabajan con sus familias en España después de cierto periodo de tiempo deciden asentarse. Un interlocutor de Sliven (Bulgaria del Sur) es de familla de músicos militares y hoy en día vive con su familia en Murcia. Él da clases de música en un club cultural. Además el interlocutor con sus hijos tocan delante de la catedral de Murcia y también los españoles les invitan a tocar a sus bodas.

El futuro de los inmigrantes empieza a proyectarse en España y su intención de volver a Bulgaria queda en un futuro indeterminado. Algunos informadores comparten que tienen la intención de quedarse en el extranjero hasta jubilarse. El dinero que se gana se invierte en el pago del crédito de la vivienda, en asegurar 


\section{perifèria}

Número 12, mes 2010

www.periferia.name

una vida tranquila y buena para la familia (incluso la salida de vacaciones todos los años) y el dinero que se ahorra está destinado a la educación de los hijos. Muchos gitanos siguen ahorrando dinero para la construcción o compra de inmuebles en Bulgaria, este proceso se ve más fuertemente expresado en los rudari. Poco a poco las relaciones con los parientes más lejanos o los conocidos del pueblo natal se rompen. Los casos en que se pide ayuda de los vecinos españoles son cada vez más frecuentes. Así por ejemplo en la visita de un médico uno puede preferir que algún español vaya con el enfermo para asegurarse de que los médicos van a prestar atención a la gravedad de su enfermedad y no le van a dar una hora dentro de un año. Lo que siguen echando de menos en mayor medida es la vida social del barrio gitano (majala). No es casual que los inmigrantes que viven más tiempo en España se ven más afectados por este sentimiento de nostalgia. Ellos esperan las vacaciones en Bulgaria con impaciencia. Puedo poner muchos ejemplos de esto pero tal vez el más representativo es de una mujer joven que vive en Burgos con su esposo desde hace 9 años. Ella no trabaja y cuida de sus dos hijos. Este año ellos volvieron a Bulgaria durante las vacaciones de su marido para ver a su familia y sacar una partida de nacimiento de su hija pequeña. Después de su regreso yo le pregunté qué tal había pasado las vacaciones en Bulgaria y ella me dijo "muy bien, en Bulgaria siempre se está muy bien, ya estoy harta de la España esa".

En la situación de crisis económica muchos de los hombres que trabajan más que nada en el sector de la construcción se quedan sin trabajo (Pajares 2009). Por eso algunas familias vuelven a Bulgaria pero con la intención de irse otra vez a España cuando termine la crisis. Otra parte prefiere quedarse en la bolsa de trabajo de España y buscarse otro empleo. Muchos de los que compraron viviendas con créditos dejan de pagar sus cuotas mensuales y se quedan a vivir en él hasta que les echen fuera.

\section{Conclusión}

Los gitanos búlgaros de los diferentes grupos se establecen a vivir en España. Su adaptación pasa por varias etapas y como resultado de esto obreros ilegales que han llegado a ganar un poco de dinero pasan a ser emigrantes que aceptan su 


\section{perifèria}

Número 12, mes 2010

www.periferia.name

nuevo modo de vida y empiezan a vivir junto con los búlgaros en una sociedad nueva para ellos. El paso de la movilidad laboral extrafronteriza a emigración duradera se realiza en el momento en que los niños nacen o llegan a vivir al extranjero donde se matricularán en una escuela y se van a socializar en las condiciones nuevas. Empieza el proceso de legalización en el nuevo país donde los emigrantes van a vivir y se amplían los contactos con los nativos. Los gitanos se adaptan con éxito al sistema de sanidad español y poco a poco parte de sus creencias tradicionales cambian.

El nuevo modo de vida y "el viaje" a España da a muchos gitanos la razón de sentirse "gitanos en Europa". Esto lleva a fin de cuentas a una imagen integral nueva de la presencia gitana en la Europa Unida.

\section{Bibliografía}

bTV: Televisión búlgara (2010). "La crisis económica y el Tratado de Lisboa prioridades de la Presidencia española de la Unión Europea - entrevista con Sr. Jorge Fuentes, embajador de España en Bulgaria], (http://www.btv.bg//story/149829-

Krizata_i_Lisabonskiyat_dogovor_\%E2\%80\%93_prioriteti_na_ispanskoto_predseda telstvo_na_ES.html).

El Mundo (2009), El correo de Burgos, jueves 4 de junio 2009. "Los inmigrantes ya no palian la caída de nativos y la Comunidad se sitúa a la cola en crecimiento", p. 17.

INE (2010), Revisión del Padrón municipal 2010. Población extranjera por sexo, comunidades y provincias y nacionalidad (www.ine.es).

Liégeois, Jean-Pierre (1999). Romi, Tsigani, Chergari [Roma, Gitanos, Viajeros]. Sofia: Litavra.

Markova, Eugenia (2008). "Trabajadores búlgaros en Madrid. Situación legal y actuación en el mercado de trabajo". Revista CIDOB d'Afers Internacionals, no 84, p. $153-178$. 


\section{perifèria}

Número 12, mes 2010

www.periferia.name

Marushiakova, Elena y Vesselin, Popov (1997). Gypsies (Roma) in Bulgaria. Frankfurt am Main: Peter Lang Verlag.

Marushiakova, Elena y Vesselin Popov (2001). "Bulgaria: Ethnic Diversity - a Common Struggle for Equality". Guy, Will (ed.). Between Past and Future. The Roma of Central and Eastern Europe. Hatfield Hertfordshire: University of Hertfordshire Press, pp. 371-388.

Marušiakova, Elena y Vesselin, Popov (2008). "Les migrations des Roms balkaniques en Europe occidentale : mobilités passées et présentes". Balkanologie, no 11 (1-2), (http://balkanologie.revues.org/index972.html).

NSI (2001), Natsionalen statisticheski institut [Instituto Nacional de Estadística] (www.nsi.bg). Prebroyavane na naselenieto po oblasti i etnicheska grupa [Censo de población de distritos y comunidad étnica].

Pajares, Miguel (2009). Inmigración y Mercado de trabajo. Informe 2009. Madrid: Ministerio de trabajo e inmigración, Grafo, S.A.

Postanovlenie no. 258, 17.12.1958 [Decreto núm. 258 del Consejo de ministros, 17.12.1958]. Tsentralen dǔrzhaven arhiv, f.1, op.28, a.e. 15.

Reyniers, Alain (1995). "Gypsy populations and their movements within Central and Eastern Europe and towards some OECD countries". International migration and labour market policies. Occasional papers. Paris: Organisation for economic cooperation and development, No.1, pp.1-38.

San Román, Teresa (1976). Vecinos gitanos. Madrid: Akal editor.

Sikimić, Biljana (ur.) (2005). Banjaši na Balkanu. Identitet etničke zajednitse [Baniashi en los Balcanes. Identidad de la comunidad étnica]. Beograd: SANU.

Slavkova, Magdalena (2007). Tsiganite evangelisti v Bŭlgariya [Gitanos evangelistas en Bulgaria]. Sofia: Pardigma.

Slavkova, Magdalena (2008). "Being Gypsy in Europe: the Case of Bulgarian Roma Workers in Spain". Balkanologie, no 11(1-2) 


\section{perifèria}

Número 12, mes 2010

www.periferia.name

(http://balkanologie.revues.org/index1102.html).

Slavkova, Magdalena (2010). "Schimbarea reprezentărilor despre viaţa emigranţilor: migraţia la muncă a rudarilor din Bulgaria in ţările mediteraneene". Şerban, Ştelu. (coord.) Teme ín antropologia socială din Europa de sud-est. Volum dedicat memoriei Profesorului Paul Stahl. Bucureşti: Editura Paideia, pp. 283-308.

Sutherland, Anne (1986). Gypsies: The hidden Americans. Illinois: Waveland Press. Viruela Martínez, Rafael (2008). "Población rumana y búlgara en España: evolución, distribución geográfica y flujos migratorios". Cuad. de Geográfia, no 84, pp. 169194.

\section{Fotos}

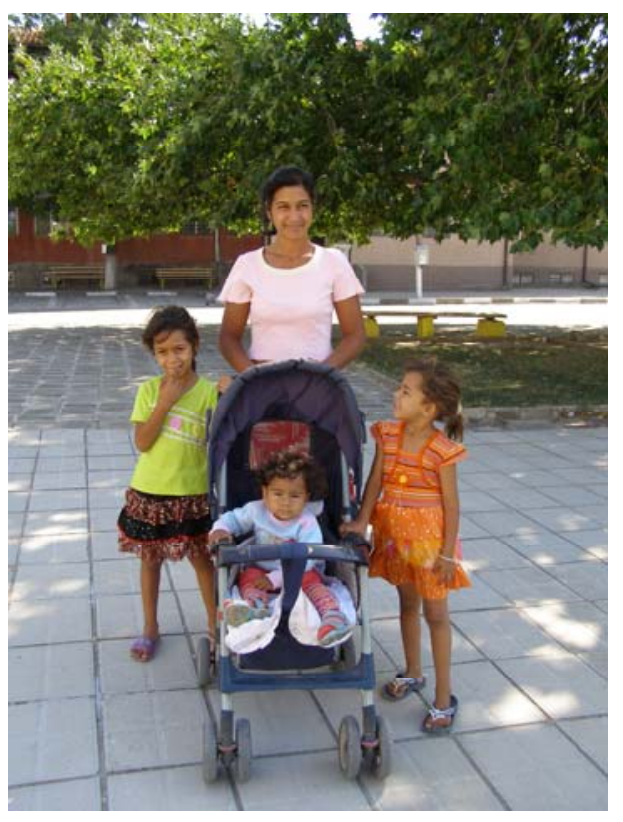

Bulgaria 2008, familia gitana, foto de Magdalena Slávkova 


\section{perifèria}

Número 12, mes 2010

www.periferia.name

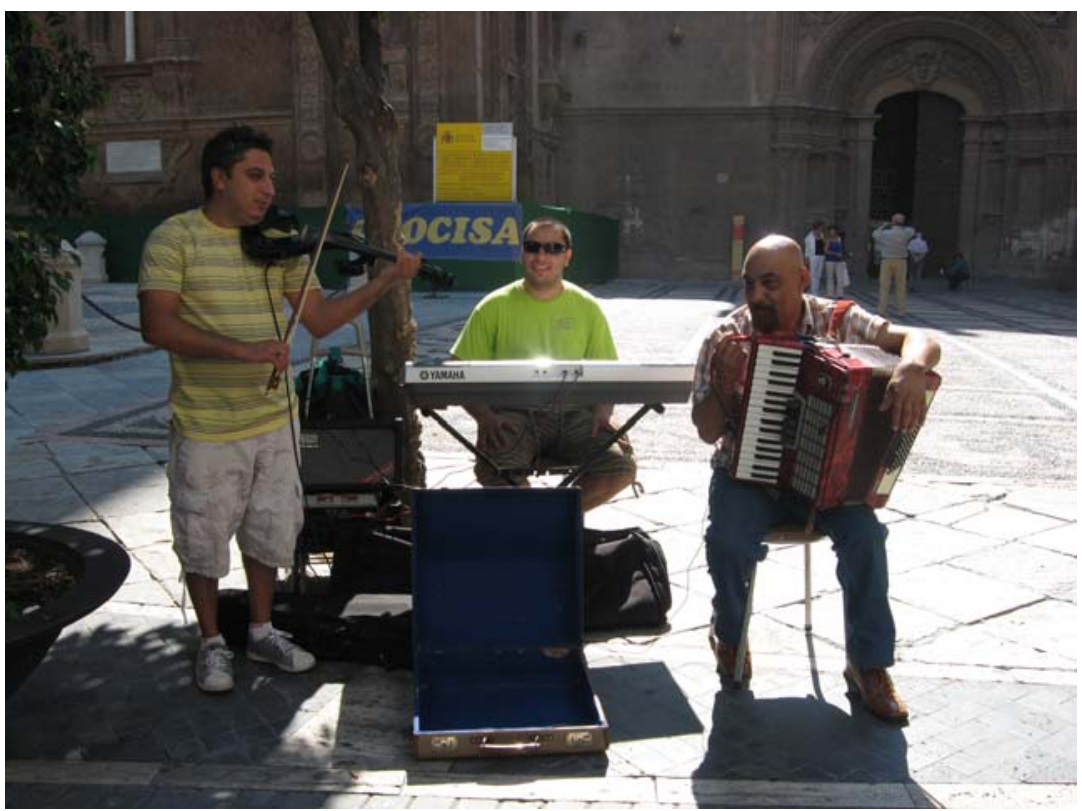

Sur de España 2009, Músicos gitanos de Bulgaria, foto de Magdalena Slávkova. 